\title{
KERAJINAN TIKAR PURUN DI KELOMPOK MASYARAKAT PIMPINAN DAERAH AISYIYAH KUALA PEMBUANG SERUYAN
}

\section{Purun Mat Crafts in the Community Group of Aisyiyah Kuala Pembuang Seruyan Regional Leaders}

\section{Nurul Hikmah Kartini* \\ Yuni Rahayu \\ Anita Rahman \\ Siti Marjanah \\ Dina Noor Laila \\ Ramadhani \\ Ifan Supiyani \\ Department of Elementary School Teacher Education, Universitas Muhammadiyah Palangkaraya, Palangka Raya, Kalimantan Tengah, Indonesia \\ *email: \\ nurulkartini77@gmail.com}

\section{Kata Kunci:}

Anyaman Tikar Purun

Kalimantan Tengah

Kearifan Lokal

Pelatihan

\section{Keywords:}

Purun Matting

Central Kalimantan

Local Wisdom

Training

\begin{abstract}
Abstrak
Kerajinan tikar purun sebagai sebuah kearifan lokal di Kalimantan Tengah harus terus dikembangkan. Minimnya masyarakat yang memproduksi tikar purun ini sebagai bagian penting dilaksanakannya pelatihan menganyam tikar purun perlu diadakan. Kelompok ibu-ibu yang biasa mengantarkan anak/cucunya yang bersekolah sebagai fokus kegiatan pengabdian masyarakat ini. Universitas Muhammadiyah Palangkaraya melalui Lembaga Penelitian dan Pengabdian kepada Masyarakat (LP2M) dan mahasiswa yang melaksanakan Kegiatan Kuliah Kerja Nyata (KKN) memberikan peran penting dalam peningkatan pengetahuan dan pembuatan produk anyaman tikar purun. Tujuan kegiatan ini adalah memberikan keterampilan, meningkatkan pengetahuan dan menghasilkan produk anyaman tikar purun pada kelompok masyarakat sasaran. Dari kegiatan pengabdian masyarakat ini disarankan agar dilakukan secara berkelanjutan pada kelompok masyarakat yang sama dilokasi tersebut dengan bentuk pelatihan yang beragam. Hal ini dilakukan agar penguasaan keterampilan semakin banyak dan membawa manfaat baik secara ekonomi maupun non-ekonomi.
\end{abstract}

\begin{abstract}
Purun mats as a pearl of local wisdom in Central Kalimantan must continue to be developed. The lack of people who produce purun mats as an essential part of carrying out the training of purun weaving mats needs to be held. The group of mothers who usually deliver their children/grandchildren who go to school is the focus of this community service activity. The Universitas Muhammadiyah Palangkaraya through the Institute for Research and Community Service (LP2M) and students carrying out the Community Service Program $(K K N)$ gave an important role in increasing the knowledge and manufacture of purun matting products. This activity aims to provide skills, improve knowledge and produce woven mats of purun in the target community groups. From community service activities, it is recommended that it be carried out sustainably in the same community groups in the location with various forms of training. This is done so that more skills are mastered and bring benefits both economically and non-economically.
\end{abstract}

(c) 2019 The Authors. Published by Institute for Research and Community Services Universitas Muhammadiyah Palangkaraya. This is Open Access article under the CC-BY-SA License (http://creativecommons.org/licenses/by-sa/4.0/). DOI: https://doi.org// 0.33084/pengabdianmu.v4il.69l.

\section{PENDAHULUAN}

Konsep Catur Dharma Perguruan Tinggi di Universitas Muhammadiyah Palangkaraya wajib dilaksanakan oleh dosen sebagai bentuk pelaksanaan dibidang akademik. Tekad ini selalu mewarnai dalam perumusan perencanaan Pengembangan Universitas Muhammadiyah Palangkaraya, maupun pelaksanaan Catur Dharma Perguruan Tinggi yaitu pendidikan dan pengajaran, penelitian, pengabdian kepada masyarakat,
Al-Islam dan Kemuhammadiyahan. Mengacu pada konsep tersebut, point pengabdian masyarakat adalah bagian penting transfer kelimuan sivitas akademika ke masyarakat (Kartini, 2017).

Universitas Muhammadiyah Palangkaraya melalui Lembaga Penelitian dan Pengabdian Masyarakat (LP2M) yang secara teknis melaksanakan program Kuliah Kerja Nyata (KKN) Angkatan ke-4l Universitas Muhammadiyah Palangkaraya, melaksanakan pengabdian 
masyarakat ini secara rutin tiap semester. Kuliah Kerja Nyata adalah bentuk pengabdian masyarakat oleh mahasiswa dengan pendekatan lintas keilmuan dan sektoran pada waktu dan daerah tertentu. Kegiatan KKN juga dilaksanakan dengan didampingi oleh para Dosen Pendamping, sehingga kegiatan yang dilakukan selalu mendapatkan pengarahan.

Sebagai bagian dari amal usaha Muhammadiyah, kampus merupakan wadah utama dalam mengembangkan beberapa program yang berkaitan erat dengan kehidupan sosial masyarakat. Kelompok-kelompok masyarakat yang berada di lingkungan amal persyarikatan Muhammadiyah merupakan mitra yang utama dalam pelaksanaan pengabdian (Purba \& Ponirin, 2013). Kegiatan pengabdian kali ini dilaksanakan di Kabupaten Seruyan, yang dengan titik fokus adalah warga masyarakat khususnya ibu-ibu di bawah naungan Pimpinan Daerah Aisyiyah Seruyan.

Kelompok ibu-ibu yang menjadi mitra dalam pengabdian ini sebagian besar adalah ibu-ibu yang mengantarkan anak mereka untuk bersekolah di TK Aisyiyah Bustanul Athfal, Jalan Kamboja, Kuala Pembuang Seruyan. Permasalahan yang teramati adalah kelompok masyarakat tersebut belum berdaya ekonomi secara maksimal, karena dari hasil wawancara awal dengan mereka, kebanyakan ibu-ibu tersebut setelah mengantarkan anak, mereka duduk dan hanya berbincang-bincang dengan teman mereka sesama ibu rumah tangga. Waktu yang ada lebih banyak dihabiskan secara percuma. Oleh karena itu, tim pengabdian masyarakat memiliki sebuah ide untuk memberikan sejenis keterampilan kepada kelompok masyarakat tersebut agar mereka bisa berkegiatan secara produktif. Kearifan lokal berupa produk-produk kerajinan dari rotan merupakan sebuah ciri khas dari Kalimantan Tengah. Pada era zaman modern sekarang, kearifan lokal tiap daerah sudah mulai tergerus oleh kemajuan teknologi digital (Mubah, 20II). Sebagai warga asli
Kalimantan Tengah, apresiasi dan kebanggaan terhadap produk lokal sangat diperlukan.

Menurut Emelia (2018), adanya pelatihan dan pendampingan yang bersifat teknis dan non teknis sangat diperlukan untuk meningkatkan kualitas produksi dan nilai lebih dari produk yang dihasilkan. Kegiatan tersebut berupa memberikan Pelatihan Menganyam Tikar kepada masyarakat setempat. Dipilihnya purun sebagai bahan anyaman karena tikar purun ini adalah produk kearifan lokal daerah setempat. Prospek kerajinan rotan sebenarnya cukup menjanjikan, namun keterbatasan pengetahuan dan keterampilan yang dimiliki masyarakat sehingga kerajinan ini masih belum banyak ditemukan disemua tempat.

\section{METODOLOGI}

Pelatihan Menganyam Tikar Purun dilaksanakan diteras sekolahan TK ABA Kuala Pembuang, Seruyan setiap jum'at, sabtu dan minggu selama bulan November 2018. Sasaran kegiatan adalah ibu-ibu yang merupakan bagian kelompok masyarakat dari Pimpinan Daerah Aisyiyah Seruyan. Untuk mencapai tujuan kegiatan, maka diperlukan metode pelaksanaan yang secara teknis yaitu:

I. Observasi awal lokasi dan sasaran kelompok masyarakat

2. Penetapan mitra yang dalam hal ini adalah Pimpinan Daerah Aisyiyah Kabupaten Seruyan.

3. Perencanaan, penyusunan panitia kegiatan

4. Membuat draft panduan pelatihan dan anggaran dana yang diperlukan.

5. Pelaksanaan kegiatan

6. Monitong dan evaluasi

\section{HASIL DAN PEMBAHASAN}

Pelatihan ini selain untuk meningkatkan pengetahuan cara pembuatan tikar, juga menghasilkan produk berupa anyaman tikar. Keterlibatan mahasiswa dalam kegiatan 
sejumlah 5 (lima) orang yang membantu tim pengabdian masyarakat yang dalam hal ini bertindak sebagai dosen pendamping lapangan. Pelatihan dilakukan pada hari Jumat, sabtu dan Minggu yang dimulai pada tanggal 09 Nopember 2018 sampai tanggal 25 Nopember 2018. Pada hari pertama pelatihan, hal pertama yang dilakukan adalah melakukan perkenalan terlebih dahulu. Baik dari pihak kami maupun pihak masyarakat sendiri.

Selanjutnya hari pertama tanggal 09 Nopember 2018 tim mengajarkan kerajinan tangan yaitu menganyam tikar dan memperkenalkan bahan-bahannya dan kegunaannya. Setelah itu pada hari selanjutnya tim mulai mempraktekkan bagaimana cara pembuatannya.setelah masyarakat sudah mulai paham tahap awal baru selanjutnya mereka mulai mempraktekannya dengan bantuan dari tim. Kendala yang ditemui adalah minimnya kami dapat yaitu bahan-bahannya terbatas karena memang agak sulit untuk menemukan bahan dasarnya yaitu purun. Kendala yang kedua yaitu masyarakat yang hadir pada waktu pelatihan menganyam tikar sebagian sudah lanjut usia, jadi agak susah melatih mereka. tetapi Alhamdulillah berkat usaha yang keras dan kemauan yang tinggi sehingga dapat terselesaikan dengan baik.

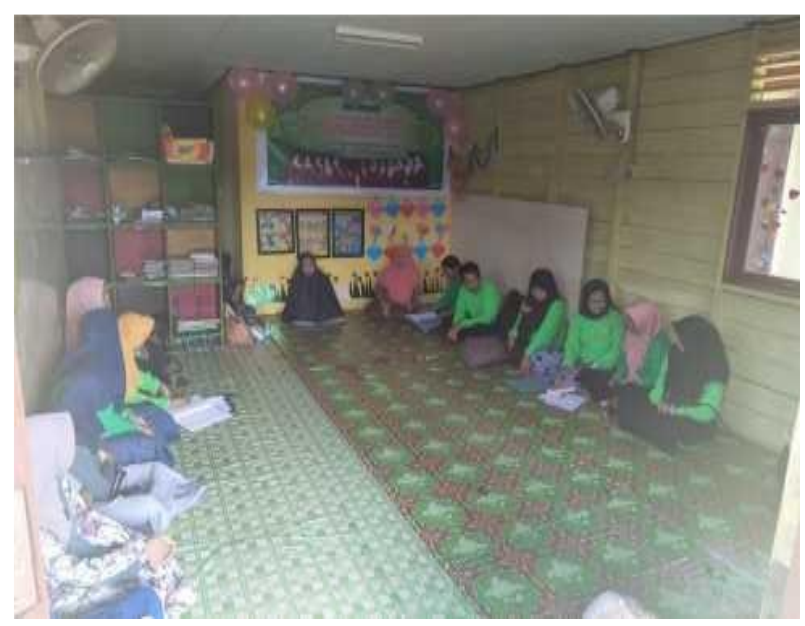

Gambar I. Rapat koordinasi antara Dosen Pendamping Lapangan, mitra dan mahasiswa

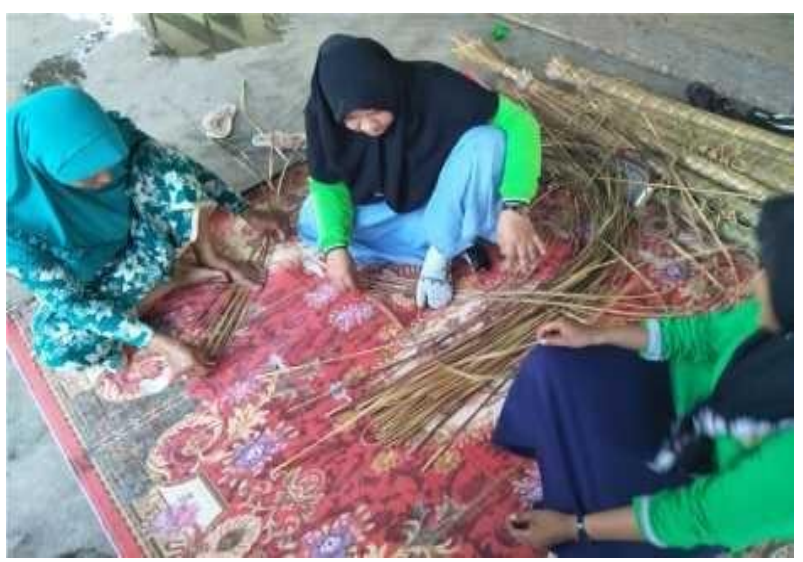

Gambar 2. Proses pelatihan menganyam tikar purun

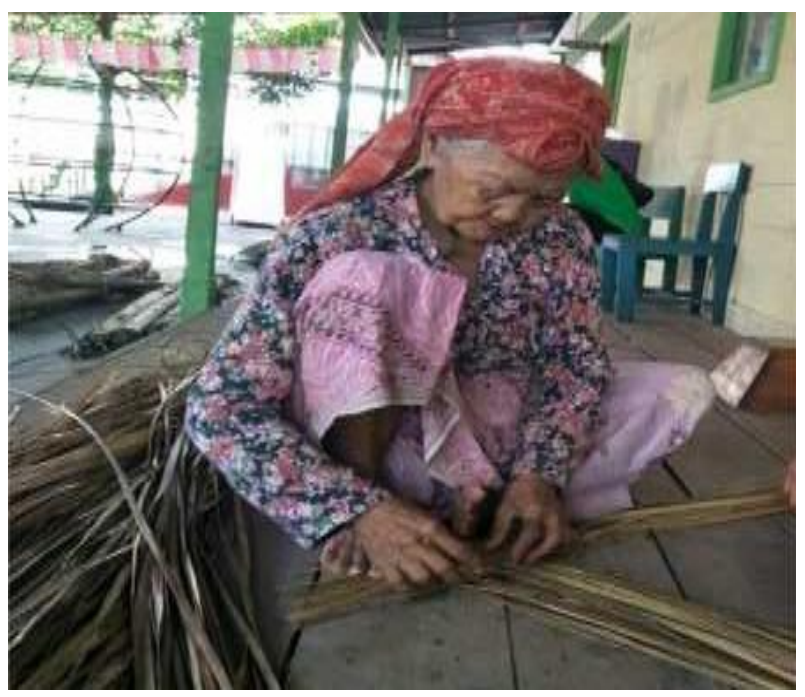

Gambar 3. Salah satu peserta pelatihan

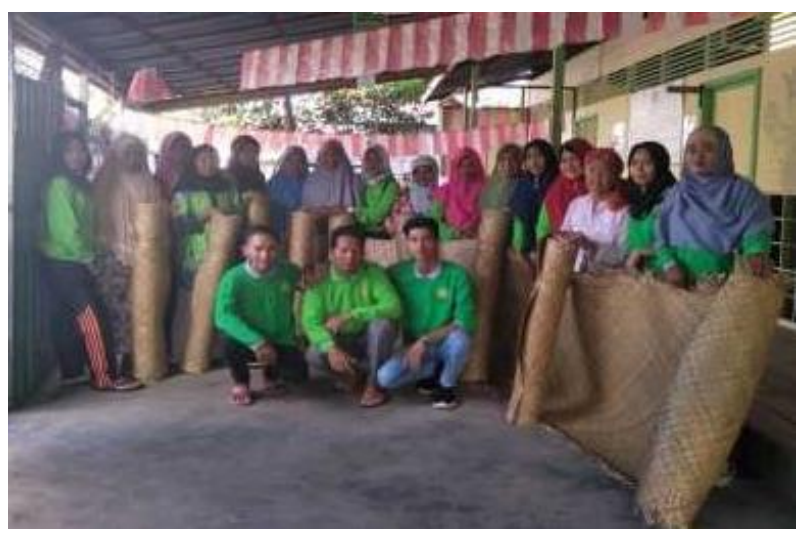

Gambar 4. Produk akhir anyaman tikar purun

\section{KESIMPULAN}

Pelatihan menganyam rotan sebagai bagian dari kegiatan pengabdian masyarakat ini memberikan dampak positif kepada masyarakat yaitu: I). Menambah pengetahuan, keterampilan dan pengalaman dari kelompok 
masayarakat; 2) meningkatkan peran pengabdian untuk memakmurkan amal usaha Muhammadiyah baik di kota maupun didaerah; 3) menumbuh kembangkan kecintaan seluruh Civitas Akademika Universitas Muhammadiyah Palangkaraya terhadap keberadaan Perguruan Muhammadiyah dan lokasi-lokasi Amal Usaha Persyarikatan Muhammadiyah. Dari kegiatan pengabdian masyarakat ini disarankan agar dilakukan secara berkelanjutan pada kelompok masyarakat yang sama dilokasi tersebut dengan bentuk pelatihan yang beragam. Hal ini dilakukan agar penguasaan keterampilan semakin banyak dan membawa manfaat baik secara ekonomi maupun non ekonomi.

\section{REFERENSI}

Emelia, T.W. 2018. Pengrajin Tikar Pandan di Desa Alue O Idi Rayeuk. Jurnal Pengabdian Kepada Masyarakat. 24(I):55 I-555.

Kartini, N.H. 20I7. Evaluasi Program Baitul Arqam bagi Karyawan di Universitas Muhammadiyah Palangkaraya. Anterior Jurnal. 16(2): I 44-I57.

Mubah, A.S. 20II. Strategi Meningkatkan Daya Tahan Budaya Lokal dalam Menghadapi Arus Globalisasi. Masyarakat, Kebudayaan dan Politik. 24(4):302-308.

Purba, I.A. \& Ponirin. 2013. Perkembangan Amal Usaha Organisasi Muhammadiyah di Bidang Pendidikan dan Kesehatan. JPPUMA: Jurnal IImu Pemerintahan dan Sosial Politik UMA (Journal of Governance and Political Social UMA). I(2): I0I-III. 